\title{
Results of Minimally Invasive Bipolar Tenotomy of Congenital Muscular Torticollis
}

\section{Resultados de tenotomia bipolar minimamente invasiva de tortícolis muscular congénita}

\author{
Ramji Lal Sahu ${ }^{1}$ \\ ${ }^{1}$ School of Medical Science and Research, Sharda University, Greater \\ Noida, Uttar Pradesh, India \\ Rev Chil Ortop Traumatol 2019;60:16-20. \\ Address for correspondence Ramji Lal Sahu, MS, School of Medical \\ Science and Research, Sharda University, 11284 Laj Building no 1, \\ Doriwalan Newrohtak Road, Karol Bagh, New Delhi 110005, India \\ (e-mail: drrlsahu@gmail.com).
}

\begin{abstract}
Keywords

- torticollis

- bipolar tenotomy

- deformity

- children

\section{Resumen}

Background Congenital muscular torticollis is the postural deformity of the head and of the neck. The purpose of the present study is to evaluate the results of bipolar sternocleidomastoid (SCM) muscle tenotomy in children.

Methods The present prospective study was conducted at the Department of Orthopedic Surgery from December 2010 to December 2014. A total of 34 children with congenital muscular torticollis and a mean age of 4.8 years (range: $1-14$ years) were recruited from the Outpatient Department. They were treated with bipolar SCM muscle release under general anesthesia. The functional and cosmetic results were rated on a scoring system modified from Lim et al (2014). All of the children were followed-up for 2 years.

Results At the final follow-up, the neck range of movement and head tilt improved and their appearance were cosmetically improved despite the long-standing nature of the deformity. The results were excellent in 30 patients (88.23\%) and good in 4 patients (11.76\%). No postoperative complications were found in any of the 34 patients.

Conclusion Bipolar tenotomy of the SCM muscle is a good method for correcting difficult cases of congenital muscular torticollis. It is a safe, effective and complicationfree method for these patients.

Introducción La tortícolis muscular congénita es la deformidad postural de la cabeza y del cuello. El propósito de este estudio es evaluar los resultados de la tenotomía del músculo esternocleidomastoideo bipolar en niños.

Métodos Este estudio prospectivo, se realizó en el departamento de Cirugía Ortopédica a partir de diciembre de 2010 a diciembre de 2014. Treinta y cuatro niños con tortícolis muscular congénita con una edad media de 4,8 años (rango: 1 a 14 años) fueron reclutados del ambulatorio. Fueron tratados con liberación de músculo esternocleidomustoide bipolar bajo anestesia general. Los resultados funcionales y cosméticos se evaluaron en un sistema de puntuación modificado de Lim y col (2014). Todos los niños recibieron acompañamiento durante dos años.
\end{abstract}

received

August 21, 2018

accepted

January 8, 2019

published online

February 21, 2019
DOI https://doi.org/

$10.1055 / \mathrm{s}-0039-1678574$. ISSN $0716-4548$.
Copyright $\odot 2019$ by Thieme Revinter

Publicações Ltda, Rio de Janeiro, Brazil
License terms

c) $(1) \$$ 


\author{
Palabras Clave \\ - tortícolis \\ - tenotomía bipolar \\ - deformidad \\ - niños
}

\begin{abstract}
Resultados En el acompañamiento final, el rango del cuello del movimiento, la inclinación y su apariencia fueron cosméticamente mejorados a pesar de la permanente naturaleza de la deformidad. Los resultados fueron excelentes en treinta pacientes $(88,23 \%)$ y bueno en cuatro pacientes $(11,76 \%)$. . No se encontraron complicaciones en el post-operatorio de esos 34 pacientes.

Conclusión La tenotomía bipolar de los esternocleidomastoideos es un buen método para corregir los casos de tortícolis muscular congénita.. Para los pacientes, es un método seguro, efectivo y sin complicaciones.
\end{abstract}

\section{Introduction}

Congenital muscular torticollis is the third most common musculoskeletal anomaly, preceded only by congenital hip dislocation and clubfoot. It is characterized by a shortening of the sternocleidomastoid muscle that leads to the tilt of the head towards the same side and the chin to the opposite side. Physical therapy yields excellent results when the anomaly is diagnosed early. Surgery is indicated for late presentation or for those with residual deformity after physical therapy. The typical presentation is a palpable mass in the SCM muscle on the affected side with a characteristic deformity. ${ }^{1,2}$ The incidence of congenital muscular torticollis varies from 0.3 to $2.0 \%$ of live births. ${ }^{3}$ If diagnosed early, physical therapy yields excellent results, with a good range of movement (ROM) of the neck and no residual deformity. Surgery is indicated for neglected cases and for those with residual deformity after physical therapy. The best time for surgery is considered to be between the ages of 1 to 4 years old. The surgical outcome is less predictable above this age group, due to permanent craniofacial deformity. ${ }^{2}$ There are different surgical techniques for the treatment of congenital muscular torticollis, such as bipolar release, unipolar release, subperiosteal lengthening, and endoscopic release of the SCM muscle. ${ }^{4}$ The surgical outcome is less predictable in relatively older children, so we have decided to study the outcome of bipolar release in children $>5$ years old. The purpose of the present study was to evaluate the results of bipolar release in children.

\section{Methods}

The present prospective study was performed in the department of orthopedic surgery from December 2010 to December 2014. It was approved by the institutional medical ethics committee. A total of 34 patients (24 male and 10 female) with congenital torticollis admitted to our institute were included in the present study. Twenty-four patients (70.58\%) were male, and 10 patients (29.41\%) were female. A total of 20 cases of torticollis were found on the right side, and 14 cases were found on the left side. ( - Table 1 ) The mean age of the patients was 4.8 years old (range: $1-14$ years old). A written informed consent was signed by the parents/guardians of the children. The patients were treated with bipolar/ unipolar SCM muscle release under general anesthesia. All of the patients were followed-up for 24 months. The inclusion criteria included age $>1$ year old, absence of any previous surgery, and absence of any known pathology that could have been the cause of the torticollis. Preoperative radiographs of the cervical spine, which had been made for all of the patients, were available for 12 patients at the time of the last follow-up. Cervicothoracic scoliosis was present in all of the patients. Radiographs of the cervical spine in two planes were included in the follow-up examination. Hip dysplasia and congenital anomalies of the feet were not present in our patients. Preoperatively, facial asymmetry had been graded as mild in 8 patients, moderate in 19 patients, and severe in 7 patients. The preoperative assessment was performed to evaluate the restriction of neck movements, head tilt and facial asymmetry, according to the scoring system of Lim et $\mathrm{al}^{2}$ (-Tables 2 and 3). Bipolar release was performed (i.e., release of both the inferior and the superior head) in 30 cases, and unipolar release (inferior pole only) in 4 cases. (-Fig. 1A, B, C, D, E, F and G) Inferior release was performed through an incision $1 \mathrm{~cm}$ above the medial third of the clavicle. The clavicular head was released completely, while the sternal head was lengthened by z-plasty. The mastoid head was released through an incision just below the tip of the mastoid process. The fascial sheaths were released, taking due precaution to not injure any neurovascular structure. The postoperative management included physiotherapy with halter traction for 3 weeks, along with passive and active movements. After 3 weeks, the patients were put on a cervical collar and the halter traction was limited to nighttime use. The patients were reviewed every month for 3 months, bi-monthly for 1 year, and thereafter every 6 months. The ROM of the neck, head tilt, and craniofacial

Table 1 Demography of the patients $(n=34)$

\begin{tabular}{|c|l|l|l|}
\hline & $\begin{array}{l}1-5 \\
\text { years old }\end{array}$ & $\begin{array}{l}5-10 \\
\text { years old }\end{array}$ & $\begin{array}{l}10-14 \\
\text { years old }\end{array}$ \\
\hline Number of patients \\
\hline Female /Male & $10 / 4$ & $8 / 4$ & $6 / 2$ \\
\hline Affected side & $6 / 8$ & $5 / 7$ & $3 / 5$ \\
\hline Left/Right & \multicolumn{5}{|l|}{} \\
\hline Type of operation & $11 / 1$ & $8 / 0$ \\
\hline $\begin{array}{c}\text { Bipolar tenotomy/ } \\
\text { unipolar tenotomy }\end{array}$ & $11 / 3$ & & \\
\hline
\end{tabular}


Table 2 Scoring system for the assessment of congenital muscular torticollis; modified from Lim et al $(2014)^{2}$

\begin{tabular}{|l|l|l|l|l|l|l|}
\hline Points & Neck movement & Head tilt & Scar & Loss of column & Lateral band & Facial asymmetry \\
\hline 3 & Full & None & Fine & None & None & None \\
\hline 2 & $<10^{\circ}$ & Mild & Slight & Slight & Slight & Slight \\
\hline 1 & $10^{\circ}-25^{\circ}$ & Moderate & Moderate & Obvious & Obvious & Moderate \\
\hline 0 & $>25^{\circ}$ & Severe & Unacceptable & Unacceptable & Unacceptable & Severe \\
\hline
\end{tabular}

Table 3 Facial asymmetry related to age groups $(n=34)$

\begin{tabular}{|l|l|l|l|l|}
\hline $\begin{array}{l}\text { Facial } \\
\text { asymmetry } \\
\text { (preoperative) }\end{array}$ & $\begin{array}{l}1-5 \\
\text { years old }\end{array}$ & $\begin{array}{l}5-10 \\
\text { years old }\end{array}$ & $\begin{array}{l}10-14 \\
\text { years old }\end{array}$ & Total \\
\hline Mild & 3 & 2 & 3 & 8 \\
\hline Moderate & 2 & 8 & 9 & 19 \\
\hline Severe & 2 & 2 & 3 & 7 \\
\hline
\end{tabular}

asymmetry were assessed, and postoperative complications (if any) were recorded. A scoring system modified from Lim et $\mathrm{al}^{2}$, which included function and cosmetic results, was used. An excellent result corresponded to $17-18$ points; a good result to 15-16 points; a fair result to 13-14 points; and a poor result to $\leq 12$ points ( - Table 4 ). The neck movement of rotation and lateral bending were measured clinically by physical therapists with a goniometer by comparing the contralateral side to the affected side. The head tilt, operative scar, loss of column, and lateral band were evaluated by clinical observation and a questionnaire. The degree of radiological head tilt was measured by determining the cervicomandibular angle (CMA), which is the angle between a line along the upper margin of the $C 7$ vertebral body and a line connecting the lower margins of the mandibular angles. ${ }^{2}$

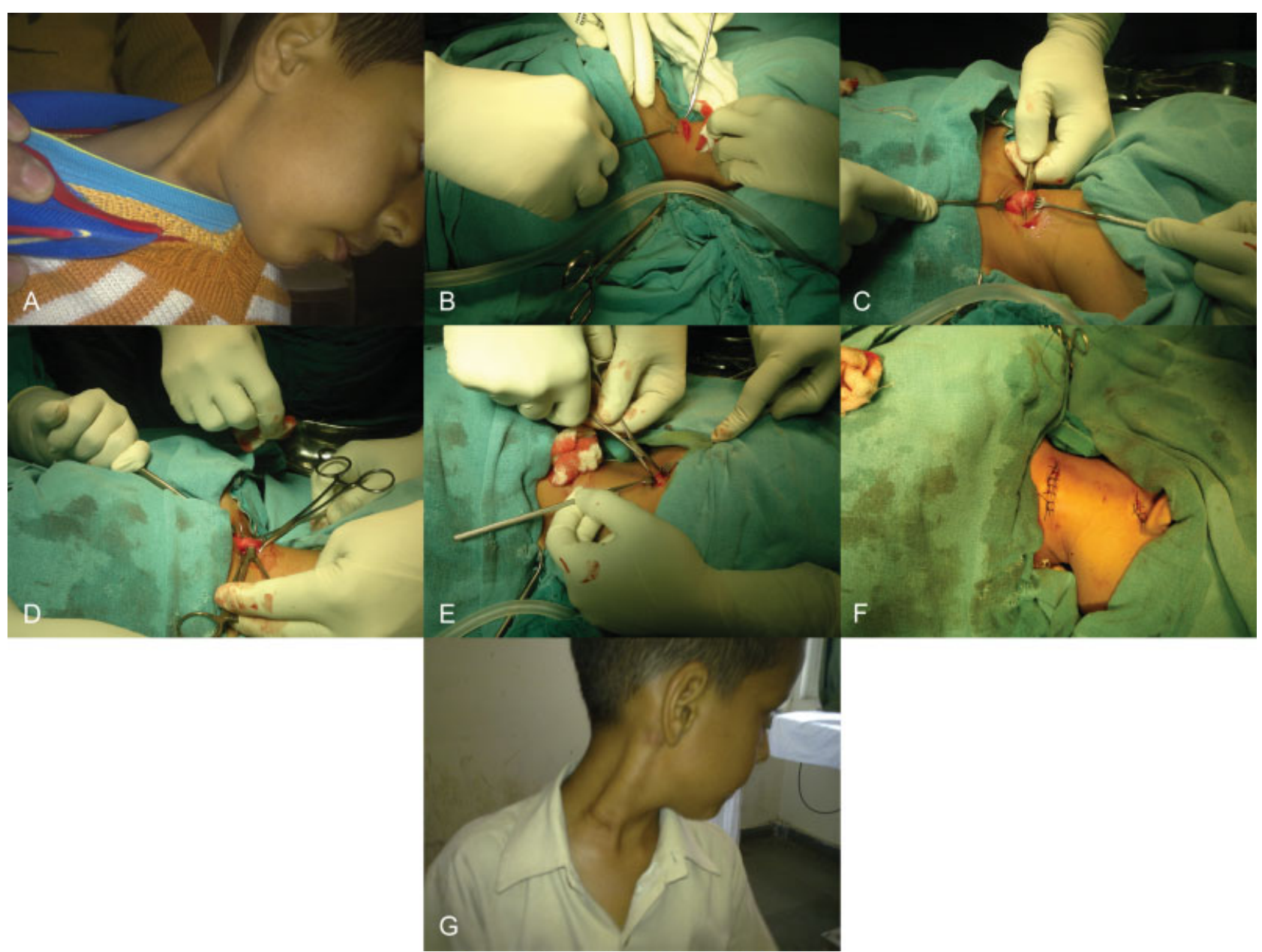

Fig. 1 (A) Preoperative view of congenital muscular torticollis showing shortening of right sternocleidomastoid muscle (SCM), head tilt to the side of SCM and rotation of the chin to the opposite side. (B) Intraoperative view - Incision at lower pole of sternocleidomastoid muscle. (C) Intraoperative view - Isolation of lower pole of sternocleidomastoid muscle. (D) Intraoperative view - Release of lower pole of sternocleidomastoid muscle. (E) Intraoperative view - Isolation and release of upper pole of sternocleidomastoid muscle. (F) Intraoperative view - Bipolar tenotomy of sternocleidomastoid muscle. (G) Postoperative view of bipolar tenotomy of sternocleidomastoid muscle. 
Table 4 Results of bipolar/unipolar tenotomy of congenital muscular torticollis $(n=34)$

\begin{tabular}{|l|l|l|l|l|}
\hline & $\begin{array}{l}1-5 \\
\text { years old }\end{array}$ & $\begin{array}{l}5-10 \\
\text { years old }\end{array}$ & $\begin{array}{l}10-14 \\
\text { years old }\end{array}$ & Total \\
\hline Excellent & 15 & 8 & 7 & 30 \\
\hline Good & 2 & 1 & 1 & 4 \\
\hline Fair & 0 & 0 & 0 & 0 \\
\hline
\end{tabular}

\section{Results}

Out of 34 patients ( 24 male and 10 female), bipolar release (i.e., release of both the inferior and the superior head) was performed in 30 cases, and unipolar release (inferior pole only) in 4 cases. The age of presentation varied between 5 and 14 years old. Out of the total sample, $70.58 \%(24 / 34)$ were male and 29.41\% (10/34) were female. The average age of presentation was 4.8 years old. Out of the total sample, $58.82 \%(20 / 34)$ of the patients had involvement of the right side, and $14.17 \%(14 / 34)$ had involvement of the left side. The mean follow-up period for the patients was of $\sim 2$ years (range: 1-3 years). The results were excellent in 30 patients (88.23\%) and good in 4 patients (11.76\%). The preoperative limitation of movement in the neck was of between $5^{\circ}$ and $10^{\circ}$ in 8 (23.52\%) cases, which was improved to between $2^{\circ}$ and $6^{\circ}$ after the surgery. The preoperative limitation of movement in the neck was of between $10^{\circ}$ and $25^{\circ}$ in 19 (26.47\%) cases, which were improved to between $2^{\circ}$ and $6^{\circ}$ after the surgery; and of $>25^{\circ}$ in 7 (20.58\%) cases, which were improved to $<10^{\circ}$ after the surgery. The preoperative head tilt was mild in $8(23.52 \%)$ patients, moderate in 19 (26.47\%), and severe in 7 (20.58\%). The postoperative head tilt was rated as none in $30(88.23 \%)$ patients, and as mild in 4 (11.76\%). The appearance of scarring was fine in 30 (88.23\%) patients, and slight in 7 (11.76\%). The loss of column was rated as none in $28(82.35 \%)$ patients, as slight in $4(11.76 \%)$, and as obvious but cosmetically acceptable in 2 (5.88\%). The presence of a lateral band was rated as none in 30 (88.23\%) patients, and as slight in $4(11.76 \%)$. The preoperative mean CMA was $15.23^{\circ}$ (range: $5.4-29.12^{\circ}$ ), which was reduced to a mean CMA of $5.3^{\circ}$ (range: $0-20^{\circ}$ ) after the surgery. Preoperatively, $7(11.76 \%)$ cases had severe to moderate facial asymmetry, and 19 (26.47\%) cases had mild facial asymmetry. After the surgery, only 4 (11.76\%) cases had minor facial asymmetry. No postoperative complications were found in any of the 34 patients. Postoperatively, there was improvement in the functional ROM of the neck in all of the patients. Postoperatively, all of the patients had acceptable levels of head tilt, as well as cosmetically acceptable scars. Sensory deficit on the ipsilateral lower ear lobe was noted in 3 cases, which was completely dissipated 3 months after the surgery. No wound infection, hematoma, or recurrence requiring surgery was encountered. No significant permanent complications occurred in any of the patients. In a subjective overall assessment, $88.23 \%$ of the patients were fully satisfied, and $11.76 \%$ were satisfied with the outcome of the treatment.

\section{Discussion}

There is no known prevention of congenital muscular torticollis. Its management depends upon the age at which the patient is presented to the orthopedic surgeon. If congenital muscular torticollis persists beyond the age of one year old, it does not resolve spontaneously. Patients with torticollis who were treated during the first year of life had better results than those treated later, and an exercise program was more likely to be successful when the restriction of motion was $<30^{\circ}$ and there was no facial asymmetry. Conservative management after the age of 1 year old was rarely successful. ${ }^{5}$ Controlled manual stretching is safe and effective in the treatment of congenital muscular torticollis when a patient is seen before the age of 1 year old. After the age of 1 year old, only between 8 and $10 \%$ of the patients required surgery. ${ }^{6}$ In addition to a complete medical history and physical examination, diagnostic procedures for congenital muscular torticollis may include X-ray and ultrasound examination. ${ }^{7}$ Ultrasonography is considered the diagnostic tool of choice for congenital muscular torticollis and can be used to rule out a tumorous condition. 5,7 Kwon et al stated that real-time sonoelastography, although an ancillary technique to conventional sonography, may predict the treatment outcomes of congenital muscular torticollis., ${ }^{8,9}$ Early diagnosis and early application of physiotherapy in congenital muscular torticollis patients are important for a successful resolution. ${ }^{5}$ Lim et $\mathrm{al}^{2}$ showed that ultrasonography-normal showed a shorter treatment duration irrespective of the severity of neck motion limitation and of the age at presentation. Additionally, manual stretching applied before the patient reaches the age of 6 months old appears to generally present a good outcome regardless of ultrasonography findings. ${ }^{10}$ The evaluation and diagnosis of congenital muscular torticollis is very important in treatment planning, and representative methods for evaluating congenital muscular torticollis include the assessment of the passive range of cervical motion, visual examination, and torticollis overall assessment (TOA) with an arthrodial goniometer and active ROM. ${ }^{11}$ Ultrasonography can be used to measure changes in angle, fascicle length, and the thickness of the muscles. ${ }^{12,13}$ The differences in the thickness of the two sternocleidomastoid muscles (DTSM) was evaluated using a LOGIQ S8 ultrasound scanner (GE Healthcare, Chicago, IL, USA) with a 6 to $12 \mathrm{MHz}$ linear array transducer. Ultrasonography of the sternocleidomastoid (SCM) muscle was performed by two physicians to confirm the existence of a neck mass or of hypertrophy of the SCM muscle; the thicknesses of the SCM muscles were measured in longitudinal and transverse views. The infants were examined in the supine position, with a slight extension of the neck caused by a gentle rotation of the head to the opposite side. ${ }^{13,14}$ The treatment of patients $<1$ year old with torticollis is conservative, consisting of physiotherapy. For patients $>1$ year old, the treatment is surgery. Between 70 and $90 \%$ of the patients $<1$ year old may be cured conservatively with physiotherapy. Surgery is the treatment of choice for patients with congenital muscular torticollis persisting after the age of one year old. There are various techniques of surgery, such as the division of both sternal and clavicular heads of SCM muscle, 
Table 5 Comparative surgical outcomes of bipolar tenotomy of congenital muscular torticollis in children $(n=34)$

\begin{tabular}{|l|l|l|l|l|l|}
\hline $\begin{array}{l}\text { Serial } \\
\text { number }\end{array}$ & Study & $\begin{array}{l}\text { Number of } \\
\text { patients }\end{array}$ & Method & Scoring system & Results \\
\hline 1 & Seyhan et al. ${ }^{1}$ & 11 & Bipolar & Neck ROM & All had satisfactory ROM \\
\hline 2 & Panigrahi et al. ${ }^{15}$ & 16 & Bipolar & Modified Lee score & Excellent: 4; good: 8; fair: 2; poor: 2 \\
\hline 3 & Current study & 34 & Bipolar/Unipolar & Modified Lee score & Excellent: 30; good: 4 \\
\hline
\end{tabular}

Abbreviations: ROM, range of motion.

and lengthening of tight SCM muscle by unipolar release,.. ${ }^{1-3}$ Lengthening of tight SCM muscle by bipolar release, subperiosteal lengthening, endoscopic release, subperiosteal lengthening, and lengthening of tight SCM muscle by unipolar or bipolar release, among other techniques, are difficult and there is a chance of injury to accessory nerves. Endoscopic surgery is a high-tech surgery and needs sophisticated instruments. Division of both sternal and clavicular heads of the SCM muscle is easy and there is a lower chance of injury to any nerves or large vessels; therefore, we perform this method for the treatment of children $>1$ year old with congenital muscular torticollis. Panigrahi ${ }^{15}$ stated that bipolar release is a very viable option for correcting neglected congenital muscular torticollis, as it brings about both functional improvement as well as improvement in cosmesis, resulting in an improvement in the quality of life. The procedure is relatively complicationfree and safe when compared with total resection of the SCM muscle. In the present study, bipolar release with z-plasty resulted in good response in patients treated late, but only with optimum surgery and very strict adherence to postoperative physiotherapy. Unipolar and bipolar release are the most popular surgical procedures employed for congenital muscular torticollis. Panigrahi et al recommended that biterminal release should be performed at between the ages of 3 and 5 years old in all patients who do not respond to nonoperative treatment, and that bipolar release combined with z-plasty preserves the normal V-contour of the SCM and ensures a better cosmetic outcome. ${ }^{15}$ We have performed the same procedure. Postoperatively, we used halter traction initially to make sure that the released structures did not return to their former tightness. After 3 weeks, the patient was shifted to a soft cervical collar, and ROM exercises were started. Regular postoperative physiotherapy was maintained. Facial asymmetry was improved in most of the patients, as well as the ROM. We have compared the surgical outcomes of bipolar tenotomy of congenital muscular torticollis in children. (- Table 5)

\section{Conclusion}

We conclude that bipolar release of the SCM muscle is a safe and effective method for treating congenital muscular torticollis even in relatively older children. This procedure presents few complications and provides good cosmetic and functional results. It resolves the deformity and restores the ROM of the neck.
Conflicts of Interests

The authors have no conflicts of interests to declare.

\section{References}

1 Seyhan N, Jasharllari L, Keskin M, Savacı N. Efficacy of bipolar release in neglected congenital muscular torticollis patients. Musculoskelet Surg 2012;96(01):55-57

2 Lim KS, Shim JS, Lee YS. Is sternocleidomastoid muscle release effective in adults with neglected congenital muscular torticollis? Clin Orthop Relat Res 2014;472(04):1271-1278

3 Angoules AG, Boutsikari EC, Latanioti EP. Congenital muscular torticollis: An overview. J Gen Pract (Los Angel) 2013;1:105

4 Das BK, Matin A, Roy RR, Islam MR, Islam R, Khan R. Congenital muscular torticollis: A descriptive study of 16 cases. Bangladesh J Child Health 2010;34(03):92-98

5 Ryu JH, Kim DW, Kim SH, et al. Factors Correlating Outcome in Young Infants With Congenital Muscular Torticollis. Can Assoc Radiol J 2016;67(01):82-87

6 Jung AY, Kang EY, Lee SH, Nam DH, Cheon JH, Kim HJ. Factors that affect the rehabilitation duration in patients with congenital muscular torticollis. Ann Rehabil Med 2015;39(01):18-24

7 Haque S, Bilal Shafi BB, Kaleem M. Imaging of torticollis in children. Radiographics 2012;32(02):557-571

8 Kwon DR, Park GY. Diagnostic value of real-time sonoelastography in congenital muscular torticollis. J Ultrasound Med 2012;31 (05):721-727

9 Lee YT, Yoon K, Kim YB, et al. Clinical features and outcome of physiotherapy in early presenting congenital muscular torticollis with severe fibrosis on ultrasonography: a prospective study. J Pediatr Surg 2011;46(08):1526-1531

10 Lee YT, Park JW, Lim M, et al. A Clinical Comparative Study of Ultrasound-Normal Versus Ultrasound-Abnormal Congenital Muscular Torticollis. PM R 2016;8(03):214-220

11 Lee SH, Kim TH, Lee BH. The effect of abdominal bracing in combination with low extremity movements on changes in thickness of abdominal muscles and lumbar strength for low back pain. J Phys Ther Sci 2014;26(01):157-160

12 Ko IH, Kim JH, Lee BH. Relationship between lower limb muscle structure and function in cerebral palsy. J Phys Ther Sci 2014;26 (01):63-66

13 Lee JY, Koh SE, Lee IS, et al. The cervical range of motion as a factor affecting outcome in patients with congenital muscular torticollis. Ann Rehabil Med 2013;37(02):183-190

14 Lee K, Chung E, Koh S, Lee BH. Outcomes of asymmetry in infants with congenital muscular torticollis. J Phys Ther Sci 2015;27(02): 461-464

15 Panigrahi R, Sahu B, Samant S. Management of neglected cases of congenital muscular torticollis with bipolar release. Int J Res Orthop 2016;2:400-403 